\title{
Diagnóstico por Ecotomografía en la Contusión Abdominal Complicada
}

\author{
Dr. Jobn Mac Kinnon D. ${ }^{1}$ \\ Ultrasonography in The Diagnosis of Complicated \\ Blunt Abdominal Trauma in Children
}

\begin{abstract}
This paper shows the experience of the author in five cascs of complicated blunt abdominal trauma in children. where ultrasonography played a mayor role in the diagnosis and follow-up of the lesions. The clinical and rtdiological dita of this children whoose complications included henoperitoneum, urinoma, subcapsular hematoma of the liver, renal fracture witl perineal hematoma and duodenal hematoma with traunatic pancreatitis, ace briefly presented. The main advantages and indications of ultrasonography in blunt abdominal trauma are discussed and it is concluded that it must be considered as a valuable tool in the diagnostic work-up of abdominal trauma in childhood.
\end{abstract}

(Key words: Abdominal Trauma. Ecotomography).

Los traumatismos abdominales son una causa frecuente de consulta en los Servicios de Urgencia pediátricos.

El aporte de la radiología al diagnóstico de sus complicaciones estaba limitado a las radiografías simples y a algunos exámenes contrastados, como la pielografía de eliminación. Actualmente se han agregado otros métodos de diagnóstico por imágenes que ofrecen opciones adicionales para evaluar los órganos de la cavidad abdominal, en busca de complicaciones ${ }^{1}$. La ecotomografia puede contribuir de manera significativa en el diagnóstico y seguimiento en estas lesiones, como se ilustra en esta presentación. En los casos que se describen se empleó un equipo digital, con método estático, tiempo real sectorial, tiempo real lineal y transductores de $3,5 \mathrm{MHZ}$ y $5 \mathrm{MHZ}$. Las imágenes se registraron en placa radiográfica, por medio de una cámara multiformato.

\section{Sujetos}

1. Niño de ocho años de edad, ingresó por una caída de altura, dolor abdominal y resistencja muscular difusa a la palpación. La radiografía de abdomen simple mostró borramiento de la silueta del psoas derecho $y$ rechazo de las asas

I. Servicio de Diagnóstico por Imágenes, Hospital Militar, Santiago. intestinales, por una masa densa de las partes blandas que ocupaba el hipocondrio y el flanco derechos (Fig. 1-A). La ecotomografía demostró una masa oyoídea, de $15 \mathrm{cms}$, de diámetro, bien delimitada, que desplazaba el rinón derecho en dirección ventral, englobando su polo superior (Fig. I B). Inmediatamente después del examen, el paciente presentó hematuria con sangre fresca y coágulos. La cirugía demostró fractura del polo superior del rinón derecho con hematoma perireflal secundario.

2. Niña de 9 años de edad, atropellada en la vía pública, ingresó por dolor abdominal y sensibilidad dolorosa difusa a la palpación. Hematocrito $39 \%$. Radiografía de abdomen simple normal. La ecotomografía demostró escasa cantidad de liquido libre en el fondo del saco de Douglas. Doce horas más tarde su hematocrito era de $33 \%$ y la ecotomografia mostraba aumento del liquido libre intraperitoneal en el que ahora flotaban algunas finas imágenes ecogénicas (Fig. 2) que se interpretaron como evidencia de hemoperitoneo. No se identificaron lesiones en los órganos abdominales. La paciente fue tratada sin cirugia ni punción abdominal. Cuatro dias después del ingreso, el liquido intraperitoneal habia desaparecido. Su hematocrito era de $36 \%$ y fue dada de alta sin otros incidentes.

3. Niño de 8 años de edad, atropellado en la vía pública 2 meses antes, consultó porque se palpaba una gran masa en el hemiabdomen dere- 
cho. Una pielografía de eliminación mostró desplazamiento del riñón derecho hacia el sector lateral y cefálico del hipocondrio ipsilateral, moderada dilatación pielocaliciaria, extravasación del medio de contraste, borramiento de la silueta del psoas derecho $y$ ausencia de imágenes del uréter derecho (Fig. 3 A). En la ecotomografia se vieron dos grandes estructuras liquidas ovoideas, que rechazaban el riñón derecho, el que presentaba moderada dilatación pielocaliciaria (Fig. 3-B). Parecía existic continuidad entre li pelvis renal y una de estas colecciones. En la intervención quirútgica se encontró cvidencia de estallido de la pelvis renal, la que se comunicaba con una colección urinaria bilobulada. Se efectuó una operación de nefrectomía derecha.
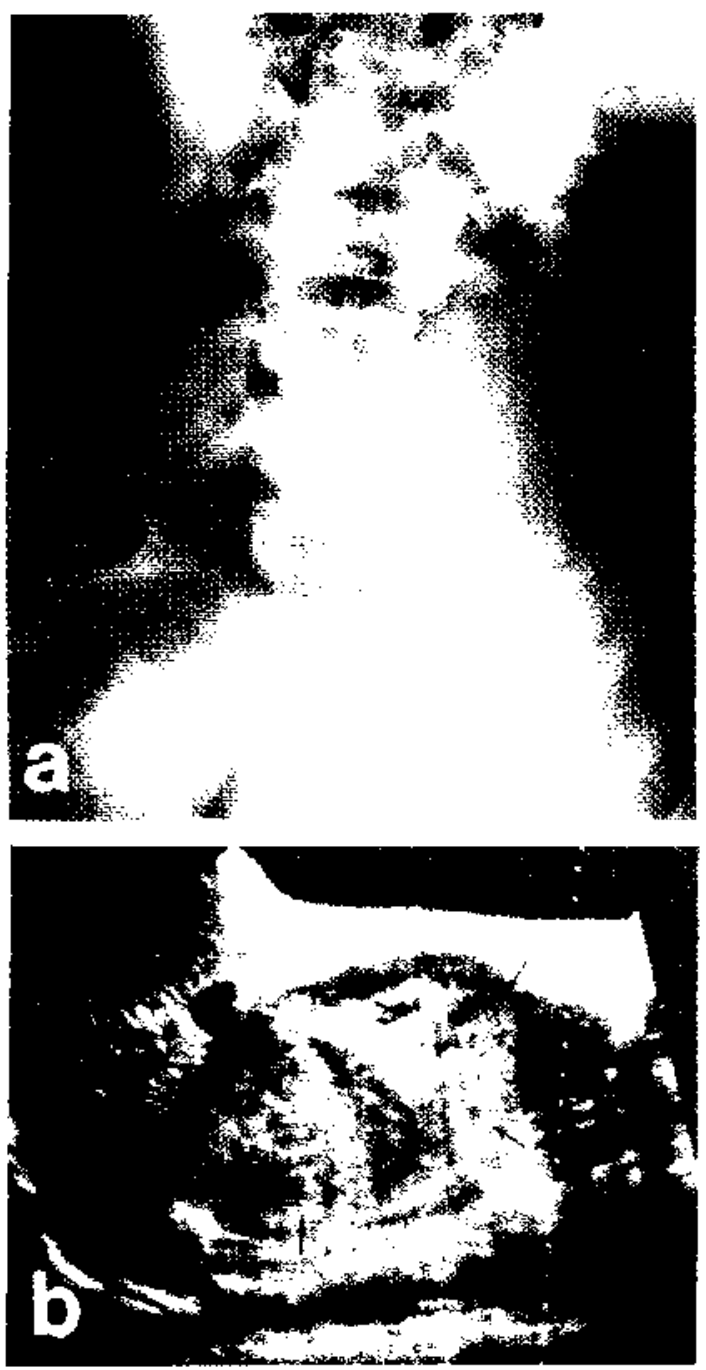

Figura 1.

A. Placa simpic que sugiere la cxistencia de una masa de] flanco derechor.

B. Corte longitudinal yuc muestrá el ritión derecho (c) desplazado hacia ventral por un hemitoma perirenal, serialado por tlechas.

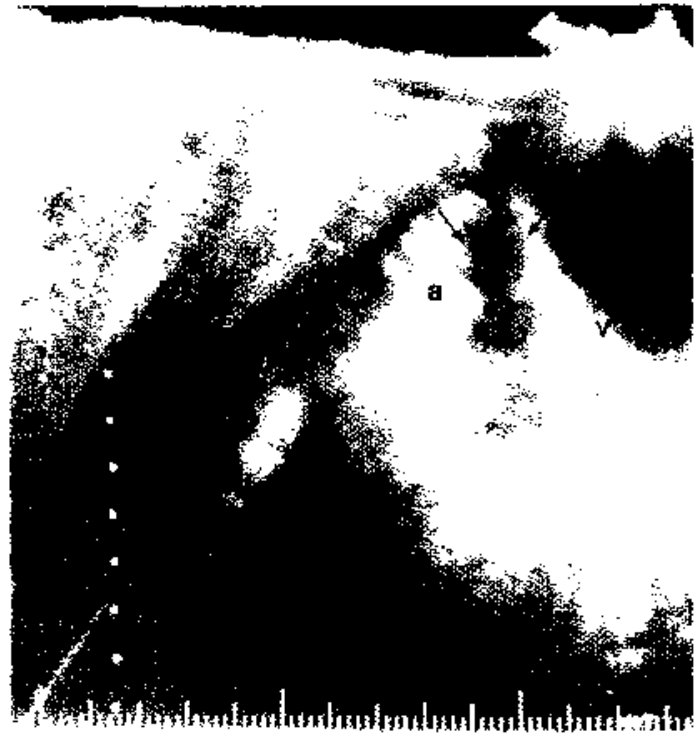

Figura 2. Liquido int taperitoneal (llechiss). que delimitu “os intestinales (a) y ol techo vesical ow)
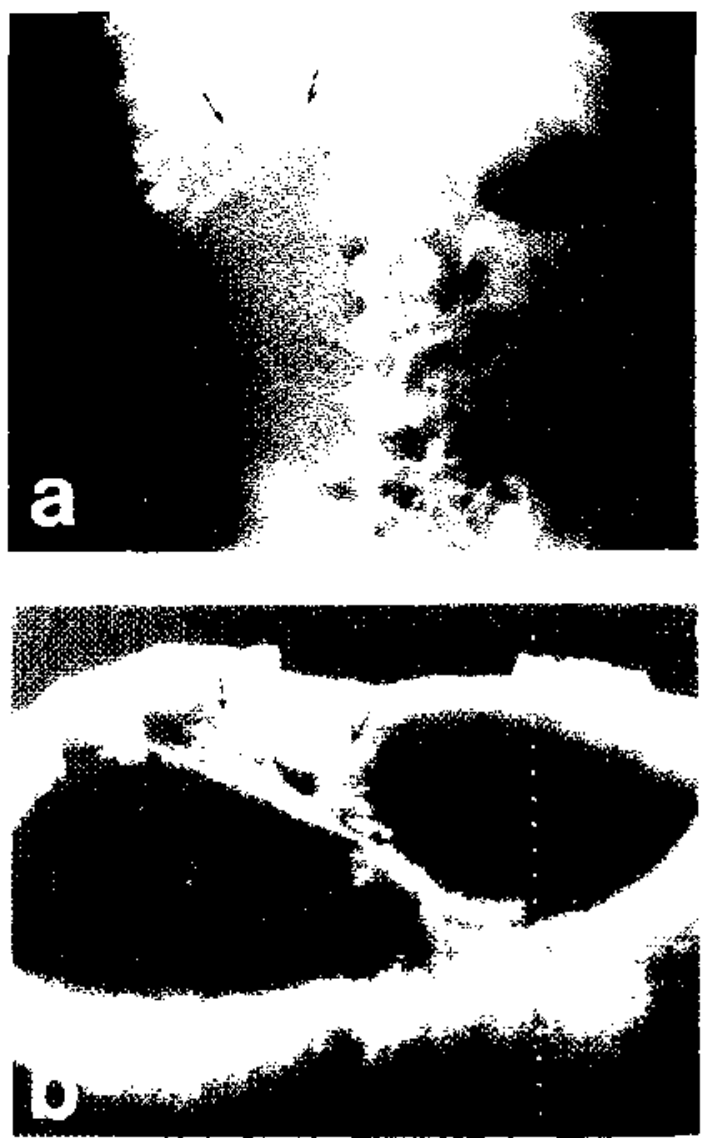

Figura 3.

A. Riñón derecho hifronetrótıco, son extravasiteón de medio de contraste (tlechus), desplazado hacia crancial. B. lin un corte longitudinal. se obsetva al riñon deresho (flechas) con diatación pielocaliciaria, dexplazado pos un gran urmoma bilobulado. 
4. Niña de 9 años, sufrió un golpe en el hipocondrio derecho, seguido por dolor abdominal, disnea y hepatomegalia. El hematocrito de ingreso fue de $33 \%$. Se hizo el diagnóstico clínico de hematoma subcapsular del hígado. Ocho dias después fue referida a nuestro hospital. El examen ecotomográfico mostró una gran colección líquida lenticular, situada periféricamente en el hipocondrio derecho, que comprimía el lóbulo derecho hepático y lo desplazaba hacia la izquierda. La lesión, que contenia finas imágenes ecugénicas con aspecto de tabiques, se extendia hacia una solución de continuidad del parénquima del lóbulo derecho del hígado. Las imáge nes se interpretaron como un hematoma subcapsular del hígado, con pequeño desgarro del parènquima (fig, 4). Un segundo control 8 días más tarde no mostró variaciones significativas. Por su evolución y condiciones estables, se manejó conservadoramente. Iiue dada de alta 40 dias después de su ingreso. No fue referida para ntevos controles.

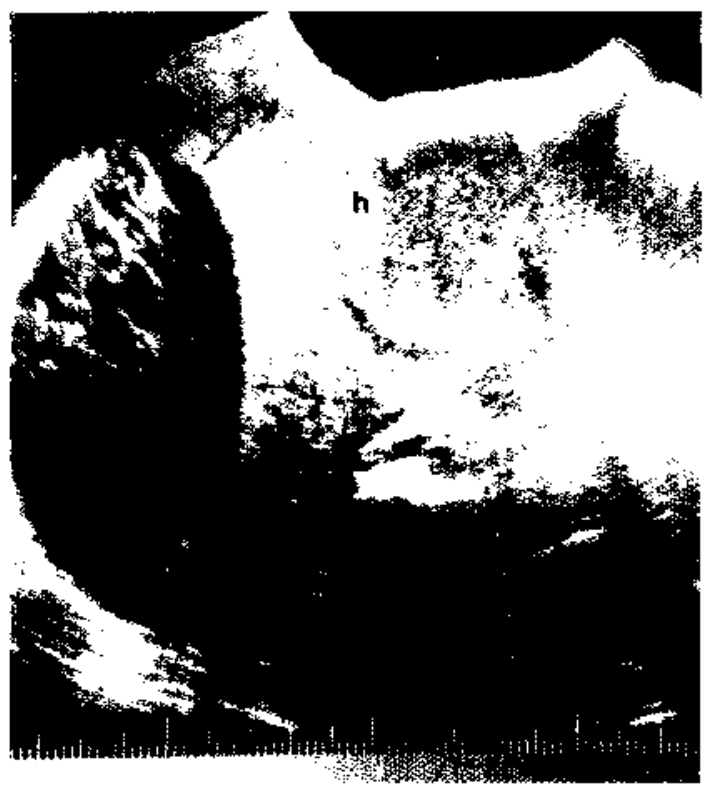

Figura 4. Corte transversal del higado (h) somprimido por un hemizioma subcapsulat, situado entre la pared lateral del bipocondrio derecho y el lóbulo derecho del higado (tlcchas)

5. Niña de 6 iños de edad, consultó por dolor abdominal y vómitos de $\mathbf{2}$ días de evolución. Se palpaba una masa redondeada en el hipocondrio derecho que parecia ser la vesicula biliar, hidrópica. La ecotomografia mostró que la vesiçula biliar estaba dilatada, el páncreas marcadamente aumentado de tamaño y que había una estructura líquida bien delimitada con algunos ecos en su interior, que parecia circunscribir el contorno lateral de la cabeza del pâncreas (Fig. 5 -.A A). El estudio radiológico digestivo permitió observar una masa de la segunda porción del duodeno con engrosamiento de los pliegues de la mucosa duodenal y obstrucción completa al tránsito del medio de contraste (Fig. 5-B), hallazgos característicos de una hematoma intramural del duodeno.
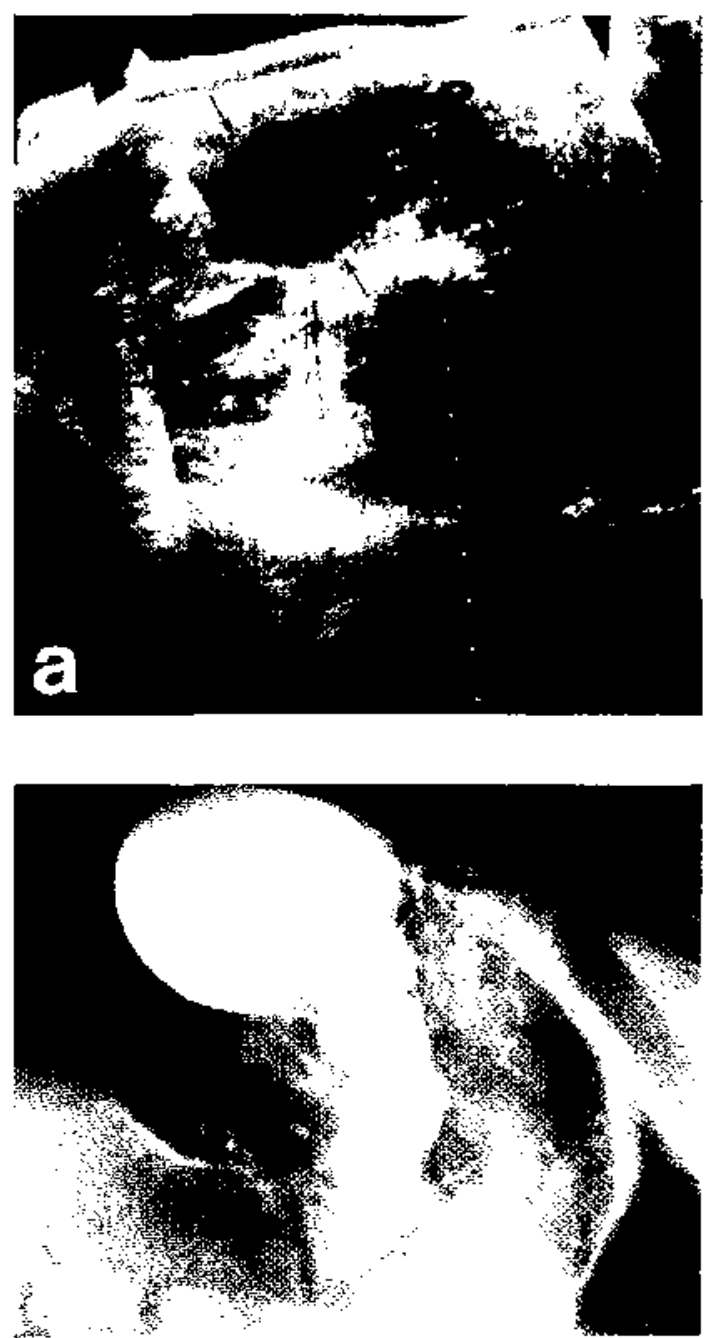

Figura 5 .

A. Masa codondeida (flechas) situada medial al riñon drecho, en la región de la cabeza del páncreas. ti cuerpo del páncséas (p) está disminuído de ceogenicidad. (Curte transversal).

B. Defictos del llenamiento de la segunda porción del duodeno, con engrosamicnto de los pliegues y obstrucción del paso del inedio de contraste, signos de hematoma intramural del duodeno.

Reinterrogada la paciente, habia sufrido un traumatismo epigastrico con el manubrio de su triciclo, el dia de comienzo de sus molestias. Las enzimas pancreáticas estaban significativamente elevadas (amilasa plasmática $3490 u$ y amilasuria 
6680u). Con el diagnóstico de pancreatitis traumática y hematona duodenal, se trató médicamente. Sucesivos controles mostraron paulatina reducción de la amilasemia, la amilasuria, el tamaño pancreático y el hematoma duodenal. Luego de 25 dias de hospitalización fue dada de alta en buenas condiciones, con restitución del tránsito digestivo.

\section{DISCUSION}

La ecotomografía se puede constituir en un importante aporte en el diagnóstico del traumatismo abdominal y sus complicaciones, en aquelos pacientes en quienes la gravedad de su cuadro clinico no obliga a una laparotomía inmediata.

En forma rapida e inoctia $y$ en ocasiones sin necesidad de movilizar al paciente desde el servicio de urgencia, es posible observar el higado, el bazo, los riñones, el páncreas, pesquisar acumullaciones anormales do liquido libre intraperitoneal y otras alteraciones estructurales.

En gerretal no requiere preparación previa ni es necesario sedar al paciente.

Las estructuras úseas y el meteorismo, afectan el rendiniento del examen. En pacientes de corta edad o con compromiso de conciencia. la imposibilidad de obtener imagenes en inspiración prolunda dificulta la evaluacron de las zonas más iltas ife ambos hipocondrios.

Lal ecolomougratsia es muy sensible para pes-

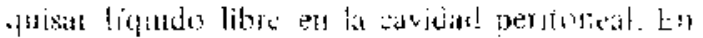

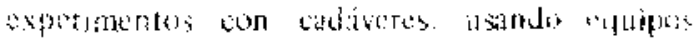

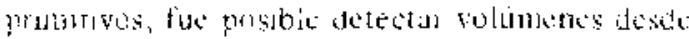

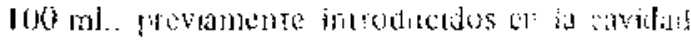

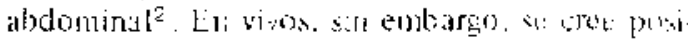
blo demistlats cantidades nenores ${ }^{3}$ das inats nes. fineales a puntiformes, suspenditas en el liquido, son muy sugerentes de sangre ditnulue esta tiecho to es constamte.

In of higado los nemalomas intraparenguimatosos se nanifiestan como areas ife distonta densidad dependiendo del tiempo de evolucieill $y$ de la existencia de coágtilos en su interiort

Los hematomas subcapsulares hepáticos aparecerl como areas liquidas, tuya forma lenticular u ovoidea los diferencia de las lesiones intraparenquimatusas $s^{5}$. En ambos casos es posible denostrar la localización y extensión.

Las lesiones pequenas y ubicadas cerca de ia cüpula hepática pueden pasar desapercibidas, especialmente si el examen se efectúa con equipos portátiles ${ }^{6}$.

En los traumatismos del bazo, el aspecto de las lesiones no difiere significativamente de las del hígado, pero el rendimiento de la ecotomografía ha sido pobre, con alta frecuencia de falsos negativos, del orden del $50 \%{ }^{6}$.
El hematoma duodenal y la pancreatitis traumática son complicaciones del traumatismo epigástrico en los niños. El primero se presenta como una masa de ecogenicidad variable. medial respecto del rin̄ón derecho, rodeando la cabeza del páncreas, pudiendo extenderse por el retroperitoneo. En algunas ocasiones es acompañado por dilatación de la via biliar ${ }^{7}$. En nuestra paciente sólo existia dilatación de la vesícula biliar (Pac. $\mathrm{N}^{-} 5$ ). La pancreatitis se manifiesta como aumento de volumen pancrético. con variaciones de la ecogenicidad de la glándula. Los controles seriados permiten demostrar la formación de seudoquistes pancreáticos ${ }^{7}$

En los traumatismos renales se pueden observar desde coágulos en la peivis renal, hasta fracturas del riñón. como ocurrió en nuestro primer caso. La ecogratía es especialmente útil para demostrar daño anatómico del riñón y extensión de la lesión al espacio perirenal y retroperito. nea $1^{\beta}$. También tiene indjcación en el diagnústico de complicaciones tardías, cono los urinomas. Los errores diagnósticos se observan functarnentalmente en pequeños desgarros o hematomas intraparenquimatosos ${ }^{6}$.

La ecotomografia también es útil en la ubservición de otras lesiones, como hematomas de la pared abdominal "dil mescnterio, que no ocurrieron en nuestro grupo de pacientes. Duratu el examen abdominal es posible demost rar derames pleviales ale peajueria magnitudi.

lebe recordarse que ia ootorngagalia pro.

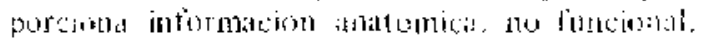

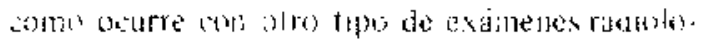

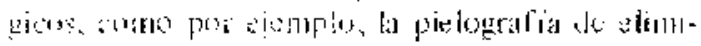

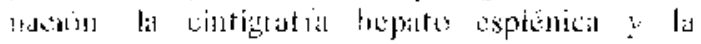

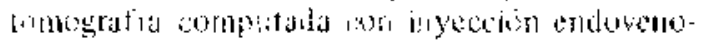
v de medio de contraste.

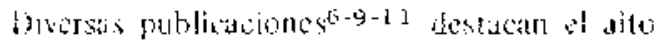

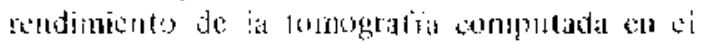

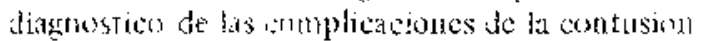

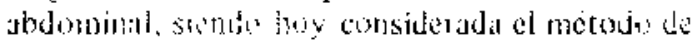
deccion en la evalusemon del tramatismo abdomistal eomplicado en pediatria6.

Sin embargo. la escaser de equipos ciue por al monento racure en nuesiro medio, su alto costo y la necesidad de usar con frecuencia sedación o anestesid en los pacientes pediátricos, Jimitan su empleo.

EJ hecho de no emplear radiaciones jonicantes, la capacidad para demostrar la anatomia abdominal y los positivos resultados obtenidos con el método. permiten afirmar que la ecotomogralia es útil en la cvaluación del paciente traumatizado. También lo es en el seguimiento de lesiones ya identificadas, sobre todo si se considera la creciente tendencia al manejo conservador de las complicaciones del traumatismo abdominal 
en los nin̄os 12 .

Se debe subrayar que un examen negativo no descarta la existencia de lesión, especiaimente si es esplénica o de la cúpula hepática. Este concepto debe tenerse aún más presente cuando exista líquido libre intraperitoneal.

\section{REFERENCIAS}

1. Jones, T.K, Walsh, J.W., Kinball I.M.: Diagnostic imaging in blunt trauma of the abolomen. Surg., Gynecol., Obst. 157: 389, 1983.

2. Goldberg, B.B., Goodman, G.A., Clearfield, H.R.: Eva]uation of ascites by ultrasound. Radiology 96 : 15,1970

3. Ferrucci, J.T.: Body ultrasonography (sccond of two parts). N. Lngl. J. Med. 300: 590, 1979.

4. Van Sontenberg. E., Simeone, JF. Mucller, P.R. et al: Sonographic appearence of hematoma in livtr, spleen and Kidney: A clinical, pathologic, and animal study. Radiology 147:507, 1983.

5. Wicks, J.D., Silver, T.M., Bree, R.L.: Grily scale features of hematomas: An ultrasonic spectrum. A.J.R. 131:977,1978.

6. Katuman, R.D., Toubin, R., Babcock, D.S., et at. Upper Abdominal trauma in children: Imaying evalution. A.J.R. 142: 449, 1984.

7. Foley, L.C. Teele, R.L.: Ultrasound of epigastric injuries after blunt trauma. A.J.R. 132: 593,1979

8. Kay, C., Rosenfield, A.T. Armm, M.: Gray-scale ultrasonography in the evaluation of renal trauma. Radiology 134: 461, 1980.

9. Berger, P.E., Kuith, J.P.: C.T. of blunt abdominal trauma in childhood. A.J.R. 136: 105, 1981.

10. Karp, M.P., Cooney, O.R., Berger, P.E., et at: The rols of computed tomography in the cualuation of blunt abdominal traumit in children. J. Pediatr. Surg. 16: 316, 1981.

11. Kuh, J.P. Berger, P.E.: Computed tomography in the evaluation of blunt abdominal trauma in childret. Radiol. Clin. Nortl. Am. 19:503, 1981.

12. Welch, K.J.: Abdommal injuries. In: Ravitch. M.M., We]ch, K.I., Bınsou, C.D. Aberdoen, F., Randolph, J.G. Pediatric Surgery Chibago: Year Book Medical Publisiner, Inc, 125-149, 1979 